\title{
Kasvihuonetomaatin viljelyn työnmenekki
}

\author{
Maritta Yläranta ja Viljo Ryynänen \\ Maanviljelystalouden laitos, Helsingin yliopisto, 00710 Helsinki 71
}

\section{Consumption of working time in glasshouse tomato production}

\author{
Maritta Yläranta and Viljo Ryynänen \\ Department of Agricultural Economics, University of Helsinki, 00710 Helsinki 71
}

\begin{abstract}
The working time consumption of glasshouse tomato in cultivating periods of various lengths, and the distribution of labour in the growth period was studied in 1977. On 10 different horticultural farms the working time hours of 15 holdings were written down. The total area of tomato was 13330 sq.m. The average size of a glasshouse was 655 sq.m.

The average working time consumption per $1000 \mathrm{sq} . \mathrm{m}$. was 1253 hours in short culture (yielding period less than 15 weeks), 1583 hours in medium long culture (yielding period 15-22 weeks) and 1998 hours in long culture (yielding period more than 22 weeks). Pinching took $28 \%$ and harvesting $16 \%$ of the total working time. Tractor work took up an average of 27 hours.

The average working time consumption per week and $1000 \mathrm{sq} . \mathrm{m}$. was 38.5 hours in short culture, 43.0 hours in medium long culture and 48.0 hours in long culture. Labour peaks occurred in planting and harvesting weeks.

The total labour output was $6.6 \mathrm{~kg} /$ hour in short culture, $7.7 \mathrm{~kg} / \mathrm{hour}$ in medium long culture and $11.0 \mathrm{~kg} / \mathrm{hour}$ in long culture.

Factors affecting the total working time consumption were studied by regression analysis. The result showed that the size of glasshouse, the level of automation, the age and training of growers and the number of permanent workers explained $76 \%$ of the variation of the total working time consumption. The unexplained part included e.g. such human factors as different working capacities of workers. On the other hand growers had various requirements of the care of the holdings.
\end{abstract}

\section{Johdanto}

Vuonna 1977 suoritetun tomaatin työnmenekkitutkimuksen tarkoituksena oli kartoittaa aluetta, jota Suomessa on tutkittu vasta vähän. Tutkimuksessa selvitettiin, mikä on tomaatinviljelyn työnmenekki eri pituisissa viljelyissä, miten kokonaistyönmenekki jakaantuu eri työvaiheisiin sekä kasvukauden eri viikoille. Toisaalta pyrittiin selvittämään myös eräitä työnmenekin suuruuteen vaikuttaneita tekijöitä.

Ruotsalaisten tutkimusten mukaan tomaatinviljelyn työkustannukset ovat keskimäärin $45 \%$ kaikista muuttuvista kustannuksista (ANON. 1971). Myös 
suomalaisilla viljelmillä työ muodostaa huomattavan osan tuotantokustannuksista. Toisaalta juuri työnkäytön alueella on käyttämättömiä mahdollisuuksia kustannusten supistamiseksi lasinalaisviljelmillä. Tulosten perusteella voidaan kiinnittää huomiota paljon työtä vaativiin menetelmiin ja työvaiheisiin sekä kehittää työtä vähentäviä menetelmiä erityisesti niitä työvaiheita varten, jotka ovat viljelyn 'pullonkauluja'. Tulokset on esitetty siten, että niitä voidaan käyttää mm. puutarhayritysten talouden suunnittelussa.

\section{Aineisto ja menetelmät}

Tutkimus suoritettiin 10 tomaattiviljelmällä, jotka sijaitsivat Uudellamaalla, Varsinais-Suomessa, Kymenlaaksossa ja Hämeessä. Työkirjanpitoa pidettiin yhteensä 15 kasvustosta. Tutkimuksen kohteena ollut yhteenlaskettu tomaatiii viljelyala oli $13330 \mathrm{~m}^{2}$.

Viljelmät erosivat toisistaan mm. kokonaisviljelyalan, kasvihuoneiden koon ja varustetason sekä viljelytekniikan osalta. Viljelmien kokonaispinta-ala oli keskimäärin $4340 \mathrm{~m}^{2}$ (vaihteluväli $1000-14000 \mathrm{~m}^{2}$ ) ja keskimääräinen kasvihuonekoko oli $655 \mathrm{~m}^{2}$ (vaihteluväli 250-1500 $\mathrm{m}^{2}$ ). Yleisimmin viljeltiin Primset- ja Sonato- lajikkeita. Tomaattia kylvettiin kalenteriviikoilla $50,51,52,1,2,7,14$ ja 18 .

Työnmenekin seuranta alkoi joulu-tammikuun vaihteessa ja jatkui koko kasvukauden 1977. Mukaan tulivat näin myös viljelykauden lopetustyöt, kuten kasvuston raivaus, kasvualustan ulosvienti tai desinfiointi ja kasvihuoneiden ym. rakenteiden pesu.

Tutkimuskauden alussa käytiin jokaisella viljelmällä selostamassa kokonaistyönmenekin ja työvaiheiden rajaamista ja opastamassa muistiinpanojen suorittamisessa. Työnmenekkitiedot merkittiin sitä varten laadituille kaavakkeille työvaiheittain ja päivittäin. Viljelijä tai työnjohtaja täytti kaavakkeet, jotka palautettiin kahden viikon välein tutkijalle. Näin oli mahdollista seurata merkintöjen huolellisuutta ja tehdä viljelijöille tarvittavat tarkkailun ja merkintöjen korjausehdotukset. Tehtyjen työtuntien merkitsemistarkkuus oli puoli tuntia.

\section{Kokonaistyönmenekki ja sen jakaantuminen}

Viljelmien vuotuinen kokonaistyönmenekki (h/1 000 brutto-m²) työvaiheittain ja viljelykauden pituuden mukaan ryhmiteltynä ilmenee taulukosta 1 . Työ on jaettu 9 työvaiheeseen. Lyhyen viljelyn (satokausi alle 15 viikkoa) keskimääräinen työnmenekki oli 1253 tuntia, keskipitkän viljelyn (satokausi 15-22 viikkoa) 1583 tuntia ja pitkän viljelyn (satokausi yli 22 viikkoa) 1998 tuntia. Traktorityötä tehtiin $1000 \mathrm{~m}^{2}$ kohti keskimäärin 27 tuntia. Työ oli pääasiassa kasvualustan sisääntuontia ja kasvuston raivaustöitä. Yksittäisistä työvaiheista eniten työtä käytettiin lehtien ja sivuversojen poistoon $(28 \%)$. Seuraavaksi eniten työtä vaati sadonkorjuu (16\%).

Tyypillisimpien tutkimusviljelmien työnmenekin viikottainen jakaantuminen viljelyajan pituuden mukaan ryhmiteltynä on esitetty kuvassa 1. Keskimääräinen työnmenekki viikkoa ja $1000 \mathrm{~m}^{2}$ kohti oli lyhyessä viljelyssä 38 tuntia, keskipitkässä viljelyssä 43 tuntia ja pitkässä viljelyssä 48 tuntia. 


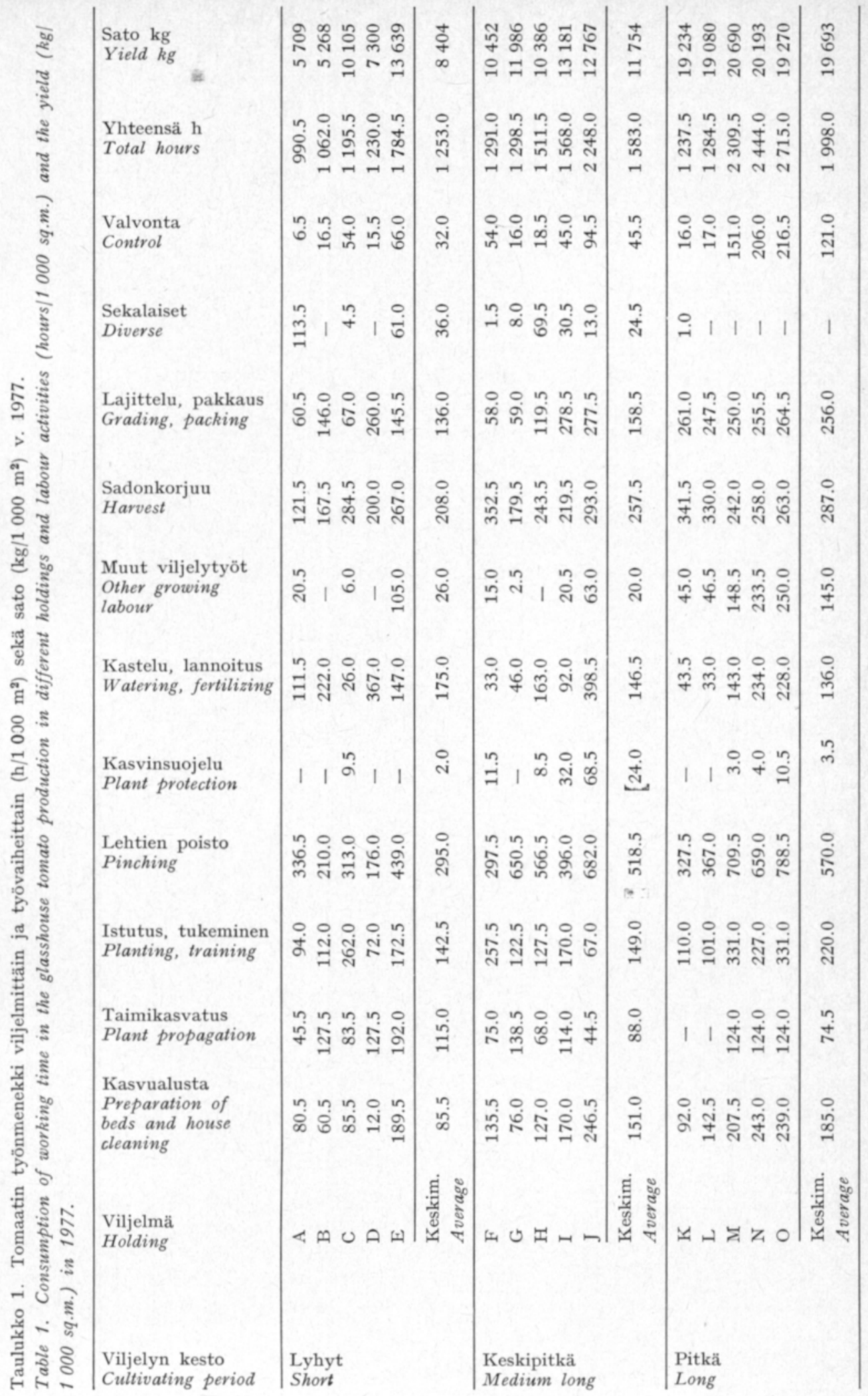


Suurimmat työhuiput olivat istutus- ja sadonkorjuuviikoilla. Noin joka toisella viljelmällä oli myös kasvuston raivausaikana suuri työhuippu. Viikottainen työnmenekki $1000 \mathrm{~m}^{2}$ kohti vaihteli keskipitkässä ja pitkässä viljelyssä noin 30 tunnista 180 tuntiin. Näin suuri työnmenekin vaihtelu aiheuttaa useassa tapauksessa suuria työvoiman käyttöongelmia. Aika ajoin työvoimalle ei ole riittävästi tuottavaa työtä ja huippukausina taas on tehtävä ylitöitä. Työvoiman käytön joustavuus auttaa ongelman ratkaisussa. Viljelmillä, joilla oma työvoima suorittaa huomattavan osan töistä, on jouston vara olennaisesti suurempi kuin runsaasti palkattua työvoimaa käyttävillä viljelmillä. Tutkimusviljelmillä työnmenekkiä tasoitetiin $\mathrm{mm}$. valitsemalla eri pituinen viljelykausi eri kasvihuoneisiin sekä viljelemällä tomaatin lisäksi muita kasveja. Näin pyrittiin jaksottamaan esim. istutus- ja sadonkäsittelytyöhuippuja viljelmän kokonaisuuden kannalta tarkoituksenmukaisesti.

Kokonaistyöntuotos ja työntuotos sadonkorjuu- ja lajittelu- sekä pakkaustöissä on esitetty taulukossa 2. Kokonaistyöntuotos oli keskimäärin $8.4 \mathrm{~kg}$

Taulukko 2. Kokonaistyöntuotos sekä työntuotokset sadonkorjuu-, lajittelu- ja pakkaustöissä $(\mathrm{kg} / \mathrm{h})$.

Table 2. The total labour output and the labour outputs in harvesting, grading and packing (kg/hour).

\begin{tabular}{|c|c|c|c|c|c|c|}
\hline \multirow[t]{2}{*}{$\begin{array}{l}\text { Viljelmä } \\
\text { Holding }\end{array}$} & \multicolumn{2}{|c|}{ Total labour output } & \multicolumn{2}{|c|}{$\begin{array}{l}\text { Työntuotos sadonkorjuu- } \\
\text { työssä } \\
\text { Labour output in } \\
\text { harvesting }\end{array}$} & \multirow{2}{*}{\multicolumn{2}{|c|}{$\begin{array}{l}\text { Työntuotos lajittelu- } \\
\text { pakkaustöissä } \\
\text { Labour output in } \\
\text { grading and packing } \\
\mathrm{kg} / \mathrm{h} \quad \text { suhdeluku } \\
\mathrm{kg} / \text { hour } \\
\end{array}$}} \\
\hline & $\begin{array}{c}\mathrm{kg} / \mathrm{h} \\
\text { kg/hour }\end{array}$ & $\begin{array}{l}\text { suhdeluku } \\
\text { ratio }\end{array}$ & $\begin{array}{c}\mathrm{kg} / \mathrm{h} \\
k g / \text { hour }\end{array}$ & $\begin{array}{l}\text { suhdeluku } \\
\text { ratio }\end{array}$ & & \\
\hline A & 5.8 & 88 & 47.0 & 117 & 94.4 & 117 \\
\hline B & 5.0 & 76 & 31.5 & 78 & 36.1 & 45 \\
\hline $\mathrm{C}$ & 8.5 & 129 & 35.5 & 88 & 150.8 & 187 \\
\hline D & 5.9 & 89 & 36.5 & 91 & 28.1 & 35 \\
\hline E & 7.6 & 115 & 51.1 & 127 & 93.7 & 116 \\
\hline $\begin{array}{l}\text { Keskim. } \\
\text { Average }\end{array}$ & 6.6 & 100 & 40.3 & 100 & 80.6 & 100 \\
\hline F & 8.1 & 105 & 29.7 & 61 & 180.2 & 160 \\
\hline G & 9.2 & 119 & 66.8 & 137 & 203.2 & 180 \\
\hline $\mathrm{H}$ & 6.9 & 90 & 42.7 & 88 & 86.9 & 77 \\
\hline I & 8.4 & 109 & 60.1 & 124 & 47.3 & 42 \\
\hline $\mathrm{J}$ & 5.7 & 74 & 43.6 & 90 & 46.0 & 41 \\
\hline $\begin{array}{l}\text { Keskim. } \\
\text { Average }\end{array}$ & 7.7 & 100 & 48.6 & 100 & 112.7 & 100 \\
\hline K & $\left.15.5^{1}\right)$ & 141 & 57.3 & 82 & 77.1 & 100 \\
\hline $\mathrm{L}^{*}$ & $\left.14.9^{1}\right)$ & 135 & 56.3 & 80 & 73.7 & 96 \\
\hline M & 9.0 & 82 & 85.5 & 122 & 82.8 & 107 \\
\hline $\mathrm{N}$ & 8.3 & 75 & 78.3 & 112 & 79.0 & 102 \\
\hline $\mathrm{O}$ & 7.1 & 65 & 73.3 & 104 & 72.9 & 95 \\
\hline $\begin{array}{l}\text { Keskim. } \\
\text { Average }\end{array}$ & 11.0 & 100 & 70.2 & 100 & 77.1 & 100 \\
\hline
\end{tabular}

1) Taimikasvustustyö ei ole mukana työnmenekissä. - Excluding the plant propagation. 

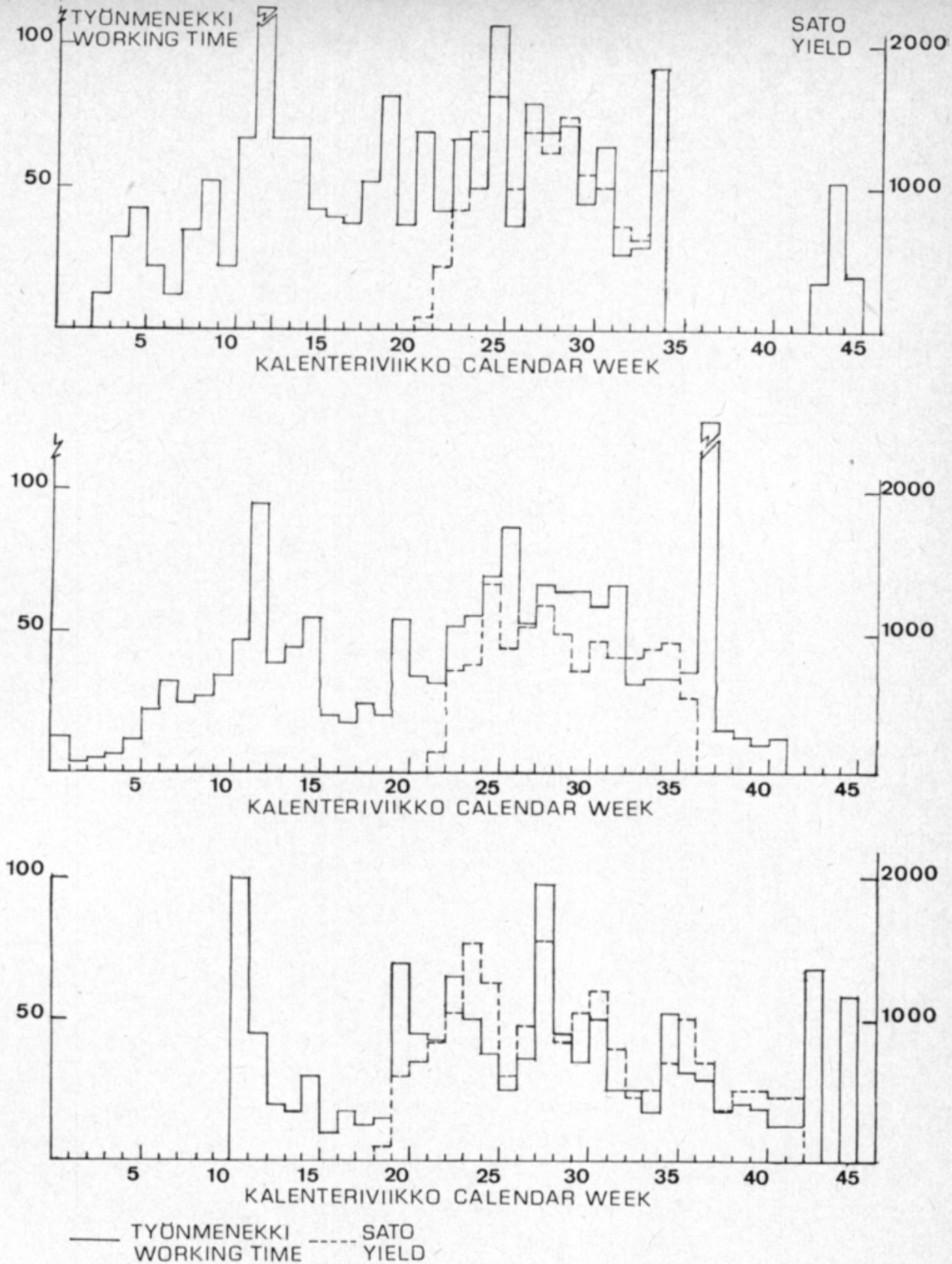

Kuva 1. Tomaatin työnmenekin $\left(\mathrm{h} / 1000 \mathrm{~m}^{2}\right)$ ja sadon $\left(\mathrm{kg} / 1000 \mathrm{~m}^{2}\right)$ jakaantuminen viikottain lyhyessä (ylin), keskipitkässä (keskimmäinen) ja pitkässä (alin) viljelyssä.

Figure 1. The distribution of the working time (hours/1 000 sq.m.) and the yield (kg/1 000 sq.m.) per week in short (above), medium long (in the middle) and long culture (below).

tomaattia tunnissa. Lyhyessä viljelyssä se oli $6.6 \mathrm{~kg}$, keskipitkässä viljelyssä $7.7 \mathrm{~kg}$ ja pitkässä viljelyssä $11.0 \mathrm{~kg}$. Sadonkorjuussa keskimääräinen työntuotos oli $53 \mathrm{~kg} / \mathrm{h}$ ja vaihteluväli $29.7-85.5 \mathrm{~kg} / \mathrm{h}$. Lajittelussa ja pakkauksessa keskimääräinen työntuotos oli $90.1 \mathrm{~kg} / \mathrm{h}$ ja vaihteluväli $28.1-203.2 \mathrm{~kg} / \mathrm{h}$. 


\section{Tulosten vertailu}

Kokonaistyönmenekki $1000 \mathrm{~m}^{2}$ kohti on ruotsalaisten tutkimusten perusteella laadituissa TEU- normeissa (ANON. 1971) lyhyessä viljelyssä 629 tuntia, keskipitkässä viljelyssä 988 tuntia ja pitkässä viljelyssä 1362 tuntia. LänsiSaksassa vastaavat normit ovat 450 tuntia, 690 tuntia ja 890 tuntia (SCHÜRMER 1973). Hollantilaisten normien mukaan lyhyt viljely vaatii noin 340 tuntia (ANon. 1972). JohANSEnin (1974) mukaan pitkä viljely vie 1515 työtuntia.

Tutkimustulosten vertaaminen yllä esitettyihin tietoihin osoittaa tavoitteellisten normien ja käytännön välillä vallitsevan eron. Näin tarkasteltuna suomalainen tomaatinviljely näyttäisi käyttävän olennaisesti enemmän ihmistyötä kuin ruotsalaiset, saksalaiset tai hollantilaiset alan normit edellyttävät. Tällä perusteella ei voida kuitenkaan sanoa, kuinka suuri työnmenekin ero olisi, jos tutkimusviljelmien tuloksia verrattaisiin ko. maiden käytännön viljelmiltä saatuihin tuloksiin.

Lyhyessä viljelyssä oli keskimääräinen työnmenekki noin kaksi kertaa ja parhaimmankin viljelmän työnmenekki noin 1.6 kertaa TEU- normeja suurempi, keskipitkässä viljelyssä vastaavat luvut olivat 1.6 ja 1.3 kertaa suuremmat. Pitkässä viljelyssä keskimääräinen työnmenekki oli 1.5 kertaa TEUnormeja suurempi, mutta parhaimman viljelmän työnmenekki oli $5 \%$ näitä pienempi. Kun lyhyen ja keskipitkän viljelyn kesto on eri maissa erilainen ja satovaihtelut huomattavat, sisältyy eri maissa saatujen tulosten vertailuun virhemahdollisuuksia. Yleispiirteenä voidaan kuitenkin esittää, että työnkäyttö tomaattiviljelmillämme näyttää olevan runsasta muiden maiden normeihin verrattuna.

\section{Työnmenekin vaihtelun syitä}

Viljelmien välinen työnmenekin ja työntuotoksen vaihtelu oli suuri. Eri pituisia viljelyjä voidaan vertailla lähinnä työtuntia kohti tuotetun tomaattimäärän avulla. Näin arvioiden tuotos oli paras pitkässä viljelyssä, jossa työntuotos oli keskimäärin $43 \%$ suurempi kuin keskipitkässä viljelyssä ja $70 \%$ suurempi kuin lyhyessä viljelyssä. Pitkässä viljelyssä kasvihuoneet olivat koko vuoden yksinomaan tomaatin viljelyssä. Lyhyessä viljelyssä huoneita käytettiin muuhun tuotantoon $15-20$ viikkoa ennen tomaatinviljelyä tai sen jälkeen.

Työvaiheittaiseen tulosten vertailuun voi sisältyä huomattavia virheitä, koska työn jakaminen eri vaiheisiin on käytännön tomaatinviljelyssä tulkinnanvaraista, ja lisäksi ajankäytön seuraaminen vaatii suurta tarkkaavaisuutta. Heikkouksista huolimatta tällainen vertailu osoittaa niitä kohtia, joissa työnmenekin vähentäminen saattaa olla helpointa. Tutkimusviljelmillä käytettiin työaikaa lehtien ja sivuversojen poistoon lyhyessä viljelyssä $23 \%$, keskipitkässä $33 \%$ ja pitkässä $29 \%$ koko työnmenekistä. Sadonkorjuuseen ja lajitteluun käytettiin vastaavasti työtä $28 \%, 26 \%$ ja $27 \%$. EкsTröмin $(1972$ a ja b)) tutkimuksen mukaan käytettiin lehtien ja versojen poistoon $25-30 \%$ sekä sadon korjuuseen ja lajitteluun $40 \%$ työajasta. TEU- normien mukaan ovat pitkän viljelyn vastaavat normit $28 \%$ ja $43 \%$ työajasta. Suunnilleen samanlaisiin tuloksiin on päätynyt myös SMEds (1977) suorittamissaan työntutki- 
muksissa. Norjalaisen Repstadin (1965) mukaan lehtien ja versojen poistoon kuluu $24 \%$ ja sadonkorjuuseen ja lajitteluun $30 \%$ työajasta.

Näihin kahteen työvaiheeseen kului tutkimusviljelmien työajasta yhteensä $51-59 \%$. EKsTröмin ja TEU- normien mukaan näihin työvaiheisiin kuluisi $70 \%$ työajasta. Suhteellisesti tarkastellen nämä työt on järjestetty tutkimustiloilla parhaiten. Työtunteina aikaa on käytetty näihin työvaiheisiin kuitenkin selvästi enemmän kuin vertailukohteissa. Kaikkiin muihin työvaiheisiin on tutkimusviljelmillä käytetty suhteellisesti ja absoluuttisesti paljon enemmän aikaa kuin normit ja esitetyt tutkimustulokset edellyttävät.

Viljelmien välistä työnmenekin vaihtelua pyrittiin selvittämään regressioanalyysillä. Työnmenekin vaihtelua selittävinä muuttujina käytettiin automaatioastetta, kokonaispinta-alaa $\left(\mathrm{m}^{2}\right)$, kasvihuonekokoa $\left(\mathrm{m}^{2}\right)$, satoa (kg/ $1000 \mathrm{~m}^{2}$ ), viljelijän ikää (vuosia), viljelijän koulutusta ja vakinaisten työntekijöiden lukumäärää. Automaatioaste määritettiin sen perusteella, kuinka suuressa määrin eräät työt (lämmitys ja lämmön säätö, kastelu, kosteuden säätö, tuuletus ja varjostus sekä sisällä tapahtuvat kuljetukset) oli automatisoitu. Tutkimuksessa käytettiin viittä eri astetta. Tasavälisen asteikon laatiminen oli tässä tapauksessa vaikeaa, koska eri työvaiheiden automatisoinnin vaikutus työnmenekkiin on absoluuttisesti tarkasteltuna eri suuri ja lisäksi eri työvaiheiden automaatioaste vaihteli viljelmittäin. Täysin automatisoitu työvaihe sai viisi pistettä ja automatisoimaton yhden pisteen. Eri työvaiheet täysin automatisoinut viljelmä sai 30 pistettä ja automatisoimaton kuusi pistettä. Koulutus pisteytettiin siten, että korkeakoulututkinnon suorittanut yrittäjä sai 4 pistettä, opiston suorittanut 3, ammattikoulun käynyt 2 ja ammattikoulutusta vailla oleva 1 pistettä.

Tutkimuksessa käytettiin lineaarista funktiota, jonka perusmuoto oli:

$$
\begin{aligned}
& \mathrm{Y}=\mathrm{a}+\mathrm{b}_{1} \mathrm{X}_{1}+\mathrm{b}_{2} \mathrm{X}_{2}+\ldots \mathrm{b}_{\mathrm{n}} \mathrm{X}_{\mathrm{n}}+\mu \text {, missä } \\
& \mathrm{X}_{1} \ldots \mathrm{X}_{\mathrm{n}} \text { ovat työnmenekin varianssia selittäviä muuttujia ja } \mu \text { on selittämättä } \\
& \text { jäänyt varianssi. }
\end{aligned}
$$

Keskimääräisen työnmenekin ja selittävien muuttujien väliset korrelaatiot olivat loogisia. Vakinaisten työntekijöiden lukumäärä ja työnmenekki olivat positiivisessa korrelaatiossa (0.55). Automaatioaste oli voimakkaasti korreloitunut kokonaispinta-alaan (0.68) ja kasvihuonekokoon (0.77). Muut korrelaatiot olivat pieniä.

Askeltavaa regressioanalyysiä käytettiin siten, että varianssia eniten selittävä muuttuja tuli ensimmäiseksi ja seuraavaksi tämän jälkeen eniten selittävä muuttuja jne. Viidennen muuttujan jälkeen selvitysaste ei juuri enää lisääntynyt. Funktio sai tällöin seuraavan muodon:

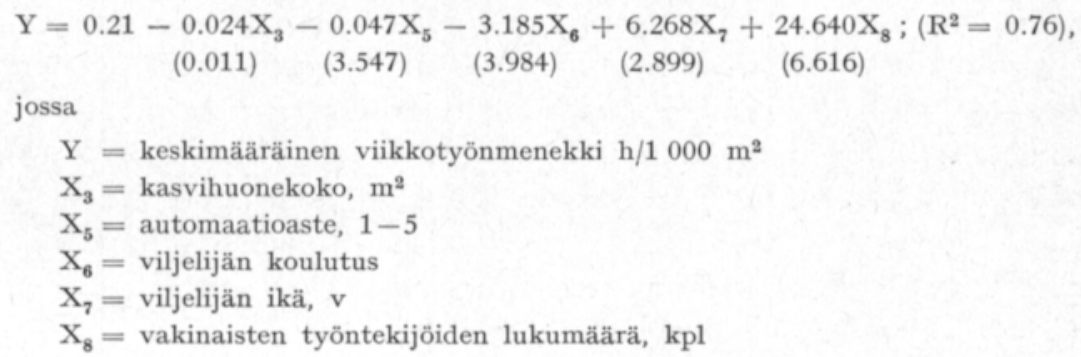


Eniten varianssia selittävä muuttuja oli automaatioaste, toiseksi työntekijöiden luku ja kolmanneksi viljelijän ikä. Kun muuttujien joukkoon lisättiin kasvihuonekoko, joka oli voimakkaassa korrelaatiossa (0.77) automaatioasteen kanssa, supistui automaatioasteen selityskyky vähäiseksi, kuten ratkaistusta funktiosta ilmenee. Viljelijän koulutusta osoittavan muuttujan selityskyky oli pieni ja tulos oli epälooginen. Tätä selittänee se, että varsinaista ammattitutkintoa vailla olleet viljelijät olivat hankkineet hyvän ammattitaidon harjoittelun ja kurssien avulla.

Suurimmat työnmenekin vaihtelua selittäneet tekijät olivat tutkimusviljelmien ryhmässä automaatioaste, vakinaisten työntekijöiden lukumäärä ja viljelijän ikä. Automatisointi vähensi työnmenekkiä merkitsevästi. Tulosta arvioitaessa on otettava huomioon, että automatisointi ja kasvihuonekoko sekä viljelmän koko ovat keskenään voimakkaassa korrelaatiossa. Työnmenekin supistumista ei ole aiheuttanut yksinomaan automatisointi, vaan myös suurissa yksiköissä tapahtuva työvoiman käytön tehostuminen. Sen sijaan viljelijän koulutus ja ikä eivät korreloineet automaatioasteen kanssa.

Kiinteän työvoiman määrän lisääntyessä työnmenekki kasvoi sekä $1000 \mathrm{~m}^{2}$ että tuotettua tomaattikiloa kohti. Sama on havaittavissa selvästi myös tarkasteltaessa työvaiheittaista työnmenekkiä. Viljelmillä, joilla oli paljon vakinaista työvoimaa, käytettiin kasvualustan valmistamiseen, lehtien poistoon, kasteluun ja lannoitukseen sekä sekalaisiin töihin runsaasti aikaa. Sen sijaan kiireisimpinä kausina (istutus, sadonkorjuu) ei ollut merkitseviä eroja runsaasti ja vähän palkattua työvoimaa käyttävien viljelmien välillä. Vain yksi viljelmä teki tästä yleislinjasta poikkeuksen. Runsaasta kiinteän työvoiman määrästä huolimatta tällä viljelmällä oli kohtuullinen kokonaistyönmenekki. On ilmeistä, että viljelmillä, joilla työn suoritti lähes yksinomaan kiinteä työvoima, työtä ei ollut aina riittävästi. Siksi tehtiin huomattavasti myös sellaista työtä, joka ei ollut tuoton kannalta välttämätöntä.

Viljelijän iän myötä työnmenekki lisääntyi merkitsevästi. Ikä oli lievässä negatiivisessa korrelaatiossa kokonaispinta-alan $(0.18)$, satomäärän $(0.17)$ ja vakinaisten työntekijöiden $(0.19)$ kanssa. Muiden muuttujien kanssa korrelaatio oli vieläkin vähäisempi.

Viljelmien välisestä työnmenekin vaihtelusta jäi selittämättä $24 \%$. Selittämättä jäänyt osa sisältää mm. erilaisten inhimillisten tekijöiden vaikutusta. Eri työntekijöiden suorituskyky on erilainen ja samankin ihmisen suorituskyky vaihtelee eri ikäkausina. Lisäksi viljelijät asettivat erilaisia vaatimuksia kasvustojen hoidolle. Tämä esteettinen puoli ilmeni mm. siten, että eräät viljelijät käyttivät myös vapaa-aikaansa viljelytöihin. Näin kertyi lähinnä lehtien ja sivuversojen poisto- sekä valvontatyötunteja.

Tutkimuksen antaman informaation perusteella voidaan todeta, että tomaattiviljelmillä tulisi kiinnittää nykyistä enemmän huomiota töiden organisointiin. Runsas lehtien ja sivuversojen poisto ei näytä vaikuttaneen sadon määrään (vaikutus sadon laatuun ei kuulunut tutkimuksen piiriin). Usein toistuvien viljelytoimenpiteiden, kuten kastelun ja lannoituksen, automatisointi on sekä työnsäästön että rasittavuuden kannalta perusteltua. Arvioimalla uudelleen eri työvaiheiden merkitystä voitaisiin vähentää niitä töitä, jotka eivät lisää satoa eivätkä paranna sen laatua. Samalla olisi mahdollista tasoittaa suuria työajan kausittaisia vaihteluita. 


\section{Tiivistelmä}

Vuonna 1977 tehdyssä tutkimuksessa selvitettiin lasinalaisen tomaatinviljelyn työvaiheittaista ja viikottaista työnmenekkiä eri pituisissa viljelyissä. Lisäksi pyrittiin löytämään syitä viljelmien välisiin työnmenekkieroihin.

Keskimääräiseksi vuotuiseksi kokonaistyönmenekiksi $1000 \mathrm{~m}^{2}$ kohti saatiin lyhyessä viljelyssä $1253 \mathrm{~h}$, keskipitkässä viljelyssä $1583 \mathrm{~h}$ ja pitkässä viljelyssä 1998 h. Yksittäisistä työvaiheista kului eniten työtä $(28 \%)$ lehtien ja sivuversojen poistoon.

Työ jakaantui kasvukauden eri viikoille useimmiten epätasaisesti. Työhuippuja aiheuttivat $\mathrm{mm}$. istutus- ja sadonkorjuutyöt.

Keskimääräinen työntuotos oli lyhyessä viljelyssä $6.6 \mathrm{~kg} / \mathrm{h}$, keskipitkässä viljelyssä $7.7 \mathrm{~kg} / \mathrm{h}$ ja pitkässä viljelyssä $11.0 \mathrm{~kg} / \mathrm{h}$. Työntuotos sadonkorjuutöissä oli keskimäärin $53.0 \mathrm{~kg} / \mathrm{h}$ ja lajittelu- ja pakkaustöissä $90.1 \mathrm{~kg} / \mathrm{h}$.

Viljelmien välisistä työnmenekkieroista selittivät $76 \%$ automaatioaste, kasvihuonekoko, viljelijän koulutus ja ikä sekä vakinaisten työntekijöiden lukumäärä. Selittämättä jäänyt osa sisälsi erilaisia inhimillisten tekijöiden vaikutuksia.

\section{KIRJALLISUUSLUETTELO}

ANoN. 1971. TEU-grönsaksodling. Lantbrukshögskolan/Alnarp. Konsulentavdelningens stencilserie. Trädgård 3. 119 p.

- 1971. Taaktijden voor sla, tomaten en komkommers. Inst. Tuinbouwtechniek. Publ. 71. Wageningen.

EкsтröM, B. 1972 a. Skörd av tomat. Redovisning och analys av arbetsstudier. Lantbrukshögskolan. Inst. Lantbr. Byggnadsteknik. Spec.medd. 14. 26 p. Lund.

- 1972 b. Arbete och avkastning in tomatodling - en fallstudie. Lantbrukshögskolan. Inst. Lantbr. Byggnadsteknik. Spec.medd. 7. 61 p. Lund.

JoHANSEN, K-I. 1974. Økonomien ved produksjon av tomat i veksthus. Gartneryrket 64, 19: $440-450$.

REPstad, R. K. 1965. Grønsaksdyrkning i veksthus. Norges Landbruksøkon. Inst. Saermelding 36: $23-45$.

SchÜrmer, E. 1973. Betriebsplanung im Intensivgemüsebau. Arbeitskreis betriebliche Beratung im Gartenbau e. V. Hannover.

Smeds, L. 1977. Arbetstudier över tomatodling. Maatalousteknologian laudaturtyö. Hels. Yliop.

Käsikirjoitus saapunut 5.3.1979 